\title{
Circadian variations of neurotransmitters in the brain - Its importance for neuroprotection
}

\author{
Francisco Estrada-Rojo ${ }^{1}$, Carolina Escobar ${ }^{2}$, and Luz Navarro ${ }^{1 *}$ \\ ${ }^{1}$ Department of Physiology; ${ }^{2}$ Department of Anatomy, Faculty of Medicine, Universidad Nacional Autonoma de México, Mexico City, Mexico
}

\begin{abstract}
Circadian rhythms are expressed at the biochemical, physiological, and behavioral level; they help to maintain the internal temporal order of an organism and allow adaptation to a cyclical environment. Circadian rhythms have a substrate at the genetic level and are synchronized to geographical cycles, as well as to other external factors, of which the main one is the light-dark cycle. Cerebral functions present circadian rhythms, which influence the neuroprotective response to acquired brain damage, such as a traumatic brain injury (TBI). Knowing the moments of greatest vulnerability to such events will allow us to offer elements to develop better study models and therapeutic objectives. Here, we present a review on diurnal variation in the levels of noradrenaline, histamine, orexin, glutamate, gamma-aminobutyric acid, serotonin, acetylcholine (ACh), and dopamine, as well as in the expression of their receptors in the brain, neurotransmission systems that may be involved in neuroprotective responses to a TBI.
\end{abstract}

Key words: Diurnal variation. Traumatic brain injury. Biological rhythms. Neuroprotection.

\section{Variaciones circadianas de los neurotransmisores en el cerebro. Su importancia para la neuroprotección}

\section{Resumen}

Los ritmos circadianos se expresan a nivel bioquímico, fisiológico y conductual; ayudan a mantener el orden temporal interno de un organismo y permiten la adaptación a un entorno cíclico. Los ritmos circadianos tienen un sustrato a nivel genético y están sincronizados con los ciclos geográficos, así como con otros factores externos, de los cuales el principal es el ciclo luz-oscuridad. Las funciones cerebrales presentan ritmos circadianos, que influyen en la respuesta neuroprotectora al daño cerebral adquirido, como un traumatismo craneoencefálico (TCE). Conocer los momentos de mayor vulnerabilidad a tales eventos nos permitirá ofrecer elementos para desarrollar mejores modelos de estudio y objetivos terapéuticos. Aquí presentamos una revisión sobre la variación diurna en los niveles de noradrenalina (NA), histamina, orexinas, glutamato, ácido gamma-aminobutírico (GABA), serotonina (5-HT), acetilcolina (ACh) y dopamina (DA), también como en la expresión de sus receptores en el cerebro; sistemas de neurotransmisión que pueden estar involucrados en respuestas neuroprotectoras a un TCE.

Palabras clave: Variación diurna. Traumatismo craneoencefálico. Ritmos biológicos. Neuroprotección.

\section{Correspondence:}

*Luz Navarro

Departamento de Fisiología

Facultad de Medicina

Universidad Nacional Autónoma de

México, Apdo. Postal 70-250

Date of reception: 04-04-2019

Date of acceptance: 20-05-2019

E-mail: Inavarro@unam.mx

DOI: 10.24875/RMN.19000069
Available online: 03-02-2020

Rev Mex Neuroci. 2020;21(1):31-38

www.revmexneurociencia.com

1665-5044/@ 2019. Academia Mexicana de Neurología A.C. Published by Permanyer. This is an open access article under the CC BY-NC-ND license (http://creativecommons.org/licenses/by-nc-nd/4.0/). 


\section{Introduction}

In the main biological processes, periodic oscillations are observed at all levels of organization, from isolated cells to complete organisms. This periodicity represents a fundamental phenomenon in biological systems conferring functional advantages in a cyclical external environment ${ }^{1}$.

These oscillations have a wide range of periods that can cover fractions of a second, such as the firing of a neuron, or cycles of 1 or more days and up to a year, such as in hibernation or the seasonal reproduction of some animals.

Some oscillations are synchronized with environmental phenomena such as the light-dark cycle, result of rotation, and terrestrial translation. Other oscillations occur even in the absence of external synchronizers, indicating that internal clocks regulate them. These are known as biological rhythms. The most studied are the circadian rhythms whose cycle is approximately 1 day 1 .

Circadian rhythms in mammals are generated by the circadian system, a group of oscillating tissues directed by an internal clock, the suprachiasmatic nucleus (SCN). However, different tissues and even isolated cells can oscillate and express periodic changes in their function. These structures, external to the SCN with their own rhythms, have been called peripheral oscillators and exist in practically all the tissues studied, including the liver and the lungs ${ }^{2}$.

\section{Circadian rhythms in health and pathology}

The circadian system transmits signals of the time to the whole organism, and consequently, all the internal processes exhibit maximum and minimum values over a period of $24 \mathrm{~h}$. These rhythms allow adaptation to a cyclical environment, making the body more efficient at times when circumstances demand it and saving effort in others. When the rhythmicity is lost or altered, there are disorders and alterations in the internal functions and in the responses of the individual to their environment, which increases the vulnerability to develop various diseases and chronic diseases. If the chronobiological alteration is corrected, the condition or damage decreases ${ }^{3}$.

Experimentally, it has been observed that the response of mice exposed to pathogens is influenced by the time at which this exposure occurs, which suggests that both the infectious capacity of the microorganisms and the immune response of the host have a circadian rhythmicity ${ }^{4}$. The vital role of the sleep-wake cycle in these interactions has also been described. For example, during slow-wave sleep, the activation of the immune system is more efficient to counteract bacterial infections and increases resistance to pathogens since it is presumed that during this period, there is higher production of some pro-inflammatory cytokines such as tumor necrosis factor-alpha or interleukin-2 that are inducers of this type of sleep 5 .

Experimental evidence suggests that the circadian regulation of some of the antioxidant systems influences the response to oxidative stress and, therefore, DNA damage, lipoperoxidation, and the oxidation of proteins. It is also known that superoxide dismutase is expressed rhythmically. Likewise, when the circadian rhythms are altered, the state of oxidative stress increases, which can impact on the state of health-disease ${ }^{6}$. This rhythmicity in antioxidant systems can be used specifically as a therapeutic target for the modulation of reactive oxygen species and, therefore, for the protection of cells.

Another clear example of the importance of circadian rhythms in the health-disease relationship is presented when analyzing the start time of a stroke, which, similar to the attack to the myocardium, has a marked diurnal rhythm. Numerous studies have shown that the time of onset of a stroke, as well as the transient ischemic attacks, occur more frequently between 6:00 and 12:00 AM, that is, when the subject initiates its activities $^{7}$. In the rat, which is a nocturnal animal, ischemia causes more significant damage, if it is induced in the hours of darkness, which is when it begins its stage of greatest activity ${ }^{8}$. We analyzed the severity of a traumatic brain injury (TBI) in relation to the time of day using the rat as a model, finding that the recovery from a TBI has diurnal variations, recovery being better if the trauma occurs in the hours of darkness compared to the hours of light ${ }^{9}$.

During an acquired brain injury, as in a TBI, two types of responses are presented: those that generate damage and those that generate neuroprotection. Among the former, the excitotoxicity produced by the excessive release of glutamate, which allows the entry of calcium, the activation of caspases promoting apoptosis, stands out. While in the neuroprotective response, the release of gamma-aminobutyric acid (GABA) inhibits the excitability and therefore, the activation of the apoptotic pathways, minimizing cell death and brain damage. This shows that both glutamate and GABA have great interference in injury processes ${ }^{10}$. The balance between damage and neuroprotection responses depends on circadian variations where the intensity and efficiency of the synaptic neurotransmission plays a preponderant role, 
fundamentally that of the glutamatergic and GABAergic systems.

In this work, we review the existing knowledge of the influence of circadian rhythms in the neuroprotection processes emphasizing the relevance of the diurnal and/or circadian variations present in the release of noradrenaline (NA), histamine, orexin, glutamate, GABA, serotonin (5-HT), and dopamine (DA), as well as in the expression of its receptors.

\section{Circadian variations in neurotransmission systems that affect the response to a TBI}

\section{The noradrenergic system as an example of diurnal variation}

A classic example of diurnal variation is observed in the noradrenergic system in the pineal gland. One of the best-documented rhythms is the secretion of melatonin, generated by the rhythmic activity of serotonin $\mathrm{N}$-acetyltransferase. This rhythm is regulated by the SCN which stimulates the cyclic release of NA from the upper cervical ganglion according to the light-dark cycle. NA binds to beta-adrenergic receptors that stimulate cyclic adenosine monophosphate (cAMP) synthesis. In the pineal gland, diurnal variations have been reported in the expression of beta-adrenergic receptors, as well as adenylate cyclase type I and cAMP. In contrast, the alpha-adrenergic receptors of the pineal gland do not present diurnal changes ${ }^{1,11}$ (Fig. 1 and Table 1).

Concerning the neuroprotective role of NA, its potent anti-inflammatory effect is known in glial cell cultures ${ }^{12}$ protecting dopaminergic cells and reducing oxidative stress $^{13}$. There is no reference to any NA rhythms involved in this process.

\section{Diurnal variations of the histaminergic system}

Histamine, a wake-promoting neurotransmitter shows diurnal variation in the hypothalamus of many species with higher levels during the waking period and lower levels during sleep; in mice, the number of neurons containing histidine decarboxylase (HDC), the key enzyme for histamine production, is higher in the dark than in the light; even in the human hypothalamus, the diurnal variation of HDC mRNA has been document$\mathrm{ed}^{14}$. Concerning the possible neuroprotective role of histamine, several clinical trials using agonists for histamine receptors, in particular for $\mathrm{H} 3$, are in process for the treatment of some neuronal diseases, such as

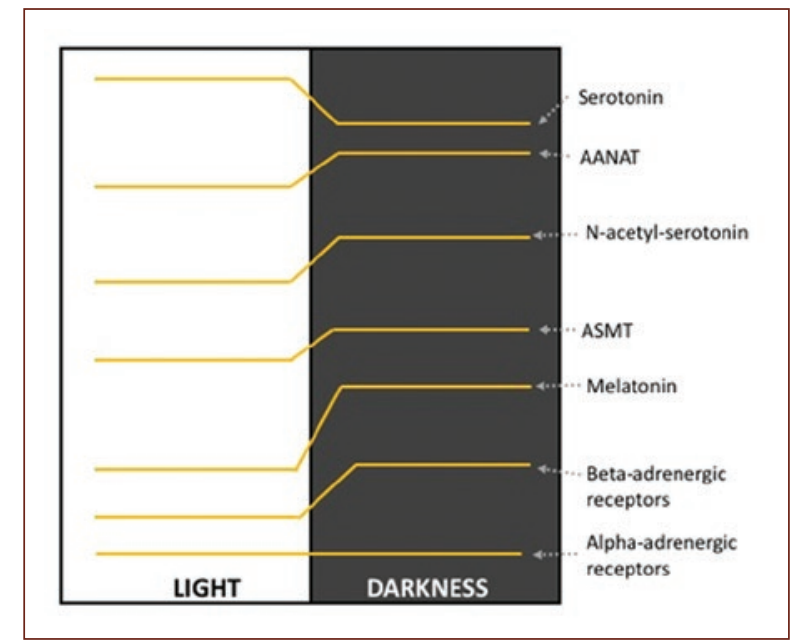

Figure 1. Variation profile of the levels of serotonin, $\mathrm{N}$-acetyl serotonin, melatonin; of the enzymes serotonin$\mathrm{N}$-acetyltransferase and acetyl-serotonin 0-methyl transferase; and of the alpha- and beta-adrenergic receptors in the pineal gland ${ }^{1,11}$.

sleep-wake disorders, neuropathic pain, attention deficit hyperactivity disorder, Alzheimer's disease, schizophrenia, and Parkinson's disease. Besides, recent studies in animal models have shown that histamine protects hippocampal neurons from excitotoxic damage induced by kainic acid and increases the neuroprotective effect of astrocytes ${ }^{15,16}$.

\section{Diurnal variations of the orexinergic system}

The orexin, hypothalamic peptides that regulate the waking state, presents diurnal variations in several species. In mice, more orexin neurons are seen in the night compared to the day, and diurnal variation of their levels in cerebrospinal fluid has been described even in humans ${ }^{14,17}$. Regarding the neuroprotective role of orexin, it has been described that they reduce neuroinflammation and infarct volume in stroke animal models; recently, it has been reported that intranasal orexin administration as post-cardiac arrest treatment in rat facilitates arousal from a coma ${ }^{18}$.

\section{Diurnal variations of the glutamatergic system}

Virtually, all the excitatory cells in the nervous system are glutamatergic, and it is estimated that more than $50 \%$ of the synapses in the brain release glutamate. 
Table 1. Maximum and minimum values of some neurotransmitters and their receptors in the brain

\begin{tabular}{|c|c|c|c|}
\hline Neurotransmitter/receptor (species) & Day & Night & Reference \\
\hline Circulating melatonin (human, rat) & $\downarrow$ & $\uparrow$ & Solís and Sánchez-Barceló, $2010^{11}$ \\
\hline $\begin{array}{l}\text { Noradrenaline in the innervation of the cervical ganglion superior } \\
\text { to the pineal gland (rat) }\end{array}$ & $\downarrow$ & $\uparrow$ & Wirz-Justice, $1987^{1}$ \\
\hline Expression of beta-adrenergic receptors in the pineal gland (rat) & $\downarrow(\mathrm{mRNA})$ & $\uparrow(\mathrm{mRNA})$ & Wirz-Justice, $1987^{1}$ \\
\hline Histamine in hypothalamic tuberomammillary region (rat) & $\downarrow$ & $\uparrow$ & McGregor et al., $2017^{15}$ \\
\hline Glutamate in SCN (hamster) & $\downarrow$ & $\uparrow$ & Glass et al., $1993^{19}$ \\
\hline Expression of GAD65 in SCN (rat) & $\uparrow(\mathrm{mRNA})$ & $\downarrow$ (mRNA) & Huhman et al., $1996^{20}$ \\
\hline Expression of NR1-NMDA in SCN (rat) & $\begin{array}{l}\uparrow \text { (RNAm) } \\
\downarrow \text { (Protein) }\end{array}$ & $\begin{array}{l}\downarrow \text { (mRNA) } \\
\uparrow \text { (Protein) }\end{array}$ & Bendová et al., $2009^{21}$ \\
\hline Expression of GLUR1-AMPA in olfactory bulb (rat) & $\downarrow(\mathrm{mRNA})$ & $\uparrow(\mathrm{mRNA})$ & Corthell et al., $2012^{25}$ \\
\hline Expression of NR1-NMDA in motor cortex (rat) & $\uparrow($ Protein) & $\downarrow$ (Protein) & Estrada-Rojo et al., $2018^{9}$ \\
\hline GABA in SCN (rat) & $\downarrow$ & $\uparrow$ & Aguilar-Roblero et al., $1993^{27}$ \\
\hline GABA in striatum (rat) & $\downarrow$ & $\downarrow$ & Choma et al., $1979^{28}$ \\
\hline Expression of $\alpha 2-G A B A a$ in median eminence (hamster) & $\uparrow$ & $\uparrow$ & Naum et al., $2001^{32}$ \\
\hline Serotonin binding in brain membrane fraction (rat) & $\downarrow$ & $\uparrow$ & Wesemann et al., $1986^{35}$ \\
\hline Brain activity of the cholinergic system (rat, hamster, mouse) & $\begin{array}{c}\downarrow \text { (inactive } \\
\text { phase) }\end{array}$ & $\begin{array}{c}\uparrow \text { (active } \\
\text { phase) }\end{array}$ & Hut and Van der Zee, $2011^{39}$ \\
\hline Dopamine in striatum (rat) & $\downarrow$ & $\uparrow$ & Castañeda et al., $2004^{27}$ \\
\hline
\end{tabular}

GABA: gamma-aminobutyric acid, SCN: suprachiasmatic nuclei, NMDA: N-methyl-D-aspartate, AMPA: $\alpha$-amino-3-hydroxy-5-methy-4-isoxazole propionate.

There are few studies on the diurnal variability of the glutamatergic system and most only analyze its variation in the SCN. Some reports indicate a higher concentration of glutamate in the SCN of hamsters during the latter part of the night, a pattern that is preserved under conditions of continuous darkness. Furthermore, it has been observed that mRNA for glutamate decarboxylase (GAD65), one of the isoforms of GAD, which catalyzes the decarboxylation of glutamate to form GABA, presents diurnal variations in the $\mathrm{SCN}$, which disappears when the animals are subjected to continuous darkness ${ }^{19,20}$ (Table 1).

In the SCN, there is also a diurnal variation in the expression of the NR2B, NR1, and NR3 subunits of the $\mathrm{N}$-methyl-D-aspartate (NMDA) receptor, with the lowest expression at $0 \mathrm{~h}$ and the highest at $20 \mathrm{~h}^{21}$ (Table 1). While the $\mathrm{Ca}^{2+}$ currents evoked by $\alpha$-amino-3-hydroxy5-methyl-4-isoxazole propionate (AMPA), present a wide distribution in the $\mathrm{SCN}$, and a diurnal rhythm with a peak during the night. Michel establishes that the communication between the right and left $\mathrm{SCN}$, as well as the degree of synchronization of the neurons of this nucleus, depends on the AMPA receptor since they are lost when it is blocked ${ }^{22}$.

Outside the SCN, it has been described that mRNA for the kainate receptor KA2 presents diurnal variations in $\mathrm{GnRH}$-ergic neurons in females whose maximum level of expression depends on the age of the rat ${ }^{23}$. Furthermore, the transporter the VGLUT1, the isoform that is mainly expressed in cerebral cortex, presents diurnal variations in synaptic vesicles obtained from mouse brain; this rhythm does not seem to depend on the synthesis of VGLUT1, but rather on the vesicular turnover ${ }^{24}$.

At the level of the olfactory bulb, recently identified as a circadian oscillator, a diurnal variation in the expression of the GluR1 subunit of the AMPA receptor has been reported. This finding could be the basis of the circadian synchronization of the action potential in the bulb and modify the synaptic interactions expected to impact olfactory coding 25 (Table 1).

NMDA receptors have been considered fundamental in brain memory and plasticity processes, in which the energetic factor could be playing an important role; in 
this sense, it has recently been reported that orexin-A inhibits the activation of these receptors by NMDA, in rat hippocampus in a time-dependent manner ${ }^{26}$.

Recently, we described a diurnal variation in the expression of the NR1 subunit of NMDA in motor cortex with a peak in the hours of light, this correlated with greater behavioral damage in rats subjected to TBI during the light phase ${ }^{9}$ (Table 1).

Although limited, the available knowledge of the diurnal variation of the glutamatergic system is of great importance. Deepening its role in different areas of the brain will make it possible to increase neuroprotective responses to a brain injury and create more effective therapeutic windows.

\section{Diurnal variations of the GABAergic system}

GABA is found in most inhibitory synapses of the brain and spinal cord.

Several authors report diurnal variations in the GABAergic system in the SCN. Even some studies indicate that GABA, in SCN, can be excitatory during daytime hours and inhibitory at night ${ }^{27}$ (Table 1).

Outside the SCN, a diurnal variation of GABA levels has been reported in the pons, the striatum, the nucleus accumbens ${ }^{28,29}$ (Table 1), the hypothalamus, in addition to the median eminence of lactating rabbits ${ }^{30}$ and the expression of the GABAa receptor, in rat cerebral cortex $^{31}$. In the hamster, a variation in the turnover of GABA in the brain has been reported, as well as the a2 subunit of the GABAa receptor in the median eminence and the $\mathrm{Kd}$ of the GABAa receptor in the cerebral cortex ${ }^{32}$ (Table 1). Even in humans, a diurnal variation in GABAergic modulation of the motor cortex inhibition has been described ${ }^{33}$.

Therefore, before a brain injury process, the neuroprotection response would be modulated by the relationship between GABA and glutamate, which varies throughout the day.

\section{Diurnal variations of the 5-HT system}

Several studies report a diurnal rhythm in the levels of 5-HT in plasma, hippocampus, hypothalamus, striatum, cerebellum, pineal gland, and $\mathrm{SCN}^{34}$, as well as for the binding of $5-\mathrm{HT}$ to rat brain membranes ${ }^{35}$, for the 5 -HT2 receptor in the frontal cortex and the lateral hypothalamus ${ }^{1}$ (Table 1).

It should be noted that the serotonergic system is phylogenetically the oldest of the neurotransmission systems, and although only a few thousand neurons release $5-\mathrm{HT}$, there is a considerable amount of target neurons so that $5-\mathrm{HT}$ acts as a thermostat that regulates internal variations with those of the environment and participates in complex processes of emotions and thoughts. It also stabilizes neuronal circuits and regulates the response of other neurotransmitters ${ }^{36}$.

Regarding the relationship of 5-HT with acquired brain injury, there are reports suggesting that inhibitors of its recapture increase neuroplasticity after a focal injury ${ }^{37}$. In the motor recovery of a TBI, the role of $5-\mathrm{HT}$ is not so clear, but its participation in post-traumatic processes such as depression, mood swings, and even Alzheimer's disease has been confirmed ${ }^{38}$.

\section{Diurnal variations of the cholinergic system}

Several studies have shown circadian fluctuations in the release of acetylcholine (ACh), in the activity of choline acetyltransferase, and in the expression of its receptors that vary notably between species and even between strains. In general, the circadian rhythmicity of the cholinergic system is characterized by a high release of ACh during the active phase of the individuals. In SCN, its rate of secretion does not appear to be endogenous but rather depends on exposure to light ${ }^{39}$ (Table 1). The superior cervical ganglion of the rat, analyzed in vitro, releases ACh with a circadian rhythm, with a maximum peak in the middle of the nocturnal phase $\mathrm{e}^{40}$. Regarding the muscarinic receptors in rat brain, it has been reported that their number is higher when the ACh levels are lower (inactive phase of the animal), and they are found in less quantity at night when the animal is more active ${ }^{41}$.

ACh has an essential role in the regulation of the sleep-wake cycle. It is considered a neurotransmitter of wakefulness, is released from basal forebrain nuclei during wakefulness and rapid eye movement (REM) sleep, and its release is dramatically reduced during slow-wave sleep (SWS). The neurons responsible for the SWS are located in the ventrolateral preoptic nucleus of the hypothalamus. They receive input from the SCN, and the retina and their firing are necessary for the maintenance of SWS. During wakefulness, their activity must be inhibited by norepinephrine from locus coeruleus nuclei and by $\mathrm{ACh}$ from the cholinergic nuclei of the basal forebrain ${ }^{39}$.

In rat TBI models, cognitive deterioration is associated with cholinergic system damage since its activation provides improvement during the recovery period of the 
brain injury ${ }^{42}$. Excessive activation of muscarinic receptors in areas $\mathrm{CA} 2$ and $\mathrm{CA} 3$ of the hippocampus in postTBI rats has also been reported, which contributes to the pathophysiological sequelae; however, it is not ruled out that this activation could be modulated by the time the injury occurs ${ }^{43}$.

The role of $\mathrm{ACh}$ in neuroprotection processes requires more studies; the fact that its receptors show differential expression during the day could provide a therapeutic window in the recovery of cognitive processes that are regulated in the cerebral cortex and hippocampus.

\section{Diurnal variations of the dopaminergic system}

The release of DA follows a circadian rhythm, in structures such as the nucleus accumbens and the striatum, its rhythm is maintained under constant light conditions, but it is lost in constant darkness ${ }^{29}$ (Table 1).

At the level of the olfactory bulb, the concentration of DA varies according to the time of day, but it has not been established whether its receptors vary as well ${ }^{44}$. In the striatum, several authors have shown diurnal variations in the dopaminergic receptors ${ }^{45}$ (Table 1).

At the level of the substantia nigra, it has been documented that the circadian disruption of DA produces motor abnormalities additional to those classically described for Parkinson's disease; it is not known if this deregulation also involves its receptors ${ }^{46}$.

From the clinical point of view, various dopaminergic drugs have been used to treat successfully cognitive deficits after a $\mathrm{TB} \mathrm{I}^{47}$.

\section{Other neurotransmission systems}

Finally, circadian rhythms have been demonstrated in other neurotransmitters, for example, opioids, adenosine, and endocannabinoids; all of them have been involved in neuroprotection processes. Specifically, our group has described diurnal variations in the CB1 cannabinoid receptor in pons, hippocampus, and cerebral cortex. Both adenosine and opioids are considered as neuroprotective $e^{48,49}$, and the cannabinergic system has been identified as one of the most directly involved in neuroprotection ${ }^{50}$.

\section{Limitations}

It is worth noting that most of the studies referred to in this review were carried out in animal models, in vivo or in vitro. However, we try to refer to studies that present data from human patients. In all cases, we indicate whether the reported data were obtained from animal models or human patients.

\section{Perspectives}

Knowing the relationship between the sleep-wake cycle, the diurnal or circadian rhythms and the neurotransmission systems involved in the acquired brain damage open a window in their study as potential biomarkers or therapeutic targets. With this approach, it will probably benefit a more significant number of patients with acquired brain damage.

Our group has published that both total sleep deprivation and REM sleep for short periods have favorable consequences in the recovery of a TBI. We believe that 5-HT, NA, and several other neurotransmitters and neuromodulators may be participating in this effect. Proposing them as therapeutic objectives is beyond the scope of this review.

\section{Conclusion}

The knowledge of rhythmic variations at the brain level of neurotransmission systems is essential to establish more effective neuroprotection processes in the face of acquired brain damage. This knowledge is gaining importance; however, it is still necessary to investigate whether this variation takes place only in the release or also in the expression of the receptors of the different neurotransmitters. This information will allow us to know better the normal functioning of the brain and in general of the nervous system.

In this review, we have provided evidence that neurotransmission systems show rhythmic variations.

In acquired brain damage, whether due to an ischemic process or a TBI, knowledge of circadian rhythms will determine the most appropriate time to apply therapeutic targets, drugs, and neuroprotective strategies.

\section{Funding}

This work was supported by the PAPIIT IN 223417 project.

\section{Conflicts of interest}

There are no potential conflicts of interest for any of the authors in this scientific report. 


\section{Acknowledgments}

We would like to thank Lic. Rocio Sibaja and Francisco Estrada Bernal for the revision and corrections of the text and bibliography.

Whilst writing this review, Francisco Estrada-Rojo was Doctorate candidate in Biologocial Sciencies at the Universidad Autónoma de México (UNAM).

\section{Ethical disclosures}

Protection of human and animal subjects. The authors declare that no experiments were performed on humans or animals for this study.

Confidentiality of data. The authors declare that no patient data appear in this article.

Right to privacy and informed consent. The authors declare that no patient data appear in this article.

\section{References}

1. Wirz-Justice A. Circadian rhythms in mammalian neurotransmitter receptors. Prog Neurobiol. 1987;29:219-59.

2. Maywood ES, O'Neill JS, Reddy AB, Chesham JE, Prosser HM, Kyriacou CP, et al. Genetic and molecular analysis of the central and peripheral circadian clockwork of mice. Cold Spring Harb Symp Quant Biol. 2007;72:85-94.

3. Aréchiga $\mathrm{H}$. Los ritmos biológicos en la salud y la enfermedad. Gac Méd Méx. 1996;132:409-23.

4. Scheiermann C, Kunisaki Y, Frenette PS. Circadian control of the immune system. Nat Rev Immunol. 2013;13:190-8.

5. Yoshida K, Hashimoto T, Sakai Y, Hashiramoto A. Involvement of the circadian rhythm and inflammatory cytokines in the pathogenesis of rheumatoid arthritis. J Immunol Res. 2014;2014:282495.

6. Wilking M, Ndiaye M, Mukhtar H, Ahmad N. Circadian rhythm connections to oxidative stress: implications for human health. Antioxid Redox Signal. 2013;19:192-208.

7. Iranzo-de Riquer A, Santamaría-Cano J. Breathing disorders during sleep and the circadian rhythm of strokes. Rev Neurol. 2005;41 Suppl 3:S17-9.

8. Vinall PE, Kramer MS, Heinel LA, Rosenwasser RH. Temporal changes in sensitivity of rats to cerebral ischemic insult. J Neurosurg. 2000;93:82-9.

9. Estrada-Rojo F, Morales-Gomez J, Coballase-Urrutia E, Martinez-Vargas M, Navarro L. Diurnal variation of NMDA receptor expression in the rat cerebral cortex is associated with traumatic brain injury damage. BMC Res Notes. 2018;11:150.

10. Hamdan SG. Trauma craneoencefálico severo parte 1. Medicrit. 2005;2:107-48.

11. Solís RA, Sánchez-Barceló EJ. Glándula Pineal. $4^{\text {th }}$ ed., Ca. 74. Sydney: JAF Tresguerres Fisiología Humana; 2010.

12. Simonini MV, Polak PE, Sharp A, McGuire S, Galea E, Feinstein DL. Increasing CNS noradrenaline reduces EAE severity. J Neuroimmune Pharmacol. 2010;5:252-9.

13. Troadec JD, Marien M, Darios F, Hartmann A, Ruberg M, Colpaert F, et al. Noradrenaline provides long-term protection to dopaminergic neurons by reducing oxidative stress. J Neurochem 2001;79:200-10.

14. McGregor R, Shan L, Wu MF, Siegel JM. Diurnal fluctuation in the number of hypocretin/orexin and histamine producing: implication for understanding and treating neuronal loss. PLoS One. 2017;12:e0178573.

15. Tiligada E, Kyriakidis K, Chazot PL, Passani MB. Histamine pharmacology and new CNS drug targets. CNS Neurosci Ther. 2011;17:620-8.

16. Xu J, Zhang X, Qian Q, Wang Y, Dong H, Li N, et al. Histamine upregulates the expression of histamine receptors and increases the neuroprotective effect of astrocytes. J Neuroinflammation. 2018;15:41.

17. Salomon RM, Ripley B, Kennedy JS, Johnson B, Schmidt D, Zeitzer JM, et al. Diurnal variation of cerebrospinal fluid hypocretin-1 (Orexin-A) levels in control and depressed subjects. Biol Psychiatry. 2003;54:96-104.

18. Modi HR, Wang Q, Gd S, Sherman D, Greenwald E, Savonenko AV, et al. Intranasal post-cardiac arrest treatment with orexin-A facilitates arousal from coma and ameliorates neuroinflammation. PLoS One. 2017; 12:e0182707.

19. Glass JD, Hauser UE, Randolph W, Ferriera S, Rea MA. Suprachiasmatic nucleus neurochemistry in the conscious brain: correlation with circadian activity rhythms.J Biol Rhythms. 1993;8 Suppl: S47-52.

20. Huhman KL, Hennessey AC, Albers HE. Rhythms of glutamic acid decarboxylase mRNA in the suprachiasmatic nucleus. J Biol Rhythms. 1996:11:311-6.

21. Bendová Z, Sumová A, Mikkelsen JD. Circadian and developmental regulation of N-methyl-d-aspartate-receptor $1 \mathrm{mRNA}$ splice variants and $\mathrm{N}$-methyl-d-aspartate-receptor 3 subunit expression within the rat suprachiasmatic nucleus. Neuroscience. 2009;159:599-609.

22. Michel S, Marek R, Vanderleest HT, Vansteensel MJ, Schwartz WJ, Colwell CS, et al. Mechanism of bilateral communication in the suprachiasmatic nucleus. Eur J Neurosci. 2013;37:964-71.

23. Eyigor O, Jennes L. Expression of glutamate receptor subunit mRNAs in gonadotropin-releasing hormone neurons during the sexual maturation of the female rat. Neuroendocrinology. 1997:66:122-9.

24. Darna M, Schmutz I, Richter K, Yelamanchili SV, Pendyala G, Höltje M, et al. Time of day-dependent sorting of the vesicular glutamate transporter to the plasma membrane. J Biol Chem. 2009;284:4300-7.

25. Corthell JT, Fadool DA, Trombley PQ. Connexin and AMPA receptor expression changes over time in the rat olfactory bulb. Neuroscience. 2012;222:38-48.

26. Perin M, Longordo F, Massonnet $C$, Welker E, Lüthi A. Diurnal inhibition of NMDA-EPSCs at rat hippocampal mossy fibre synapses through orexin-2 receptors. J Physiol. 2014;592:4277-95.

27. Aguilar-Roblero R, Verduzco-Carbajal L, Rodríguez C, Mendez-Franco J, Morán J, de la Mora MP. Circadian rhythmicity in the GABAergic system in the suprachiasmatic nuclei of the rat. Neurosci Lett. 1993;157: 199-202.

28. Choma PP, Puri SK, Volicer L. Circadian rhythm of cyclic nucleotide and GABA levels in the rat brain. Pharmacology. 1979;19:307-14.

29. Castañeda TR, de Prado BM, Prieto D, Mora F. Circadian rhythms of dopamine, glutamate and GABA in the striatum and nucleus accumbens of the awake rat: modulation by light. J Pineal Res. 2004;36: 177-85.

30. Alvarez MP, Cardinali DP, Jiménez V, Alvariño M, Esquifino Al. Twenty-four hour rhythm of plasma prolactin in female rabbit pups. Correlation with hypothalamic and adenohypophysial dopamine, serotonin, gamma-aminobutyric acid and taurine content. Anim Reprod Sci. 2006;91: 143-53.

31. Acuña Castroviejo D, Rosenstein RE, Romeo HE, Cardinali DP. Changes in gamma-aminobutyric acid high affinity binding to cerebral cortex membranes after pinealectomy or melatonin administration to rats. Neuroendocrinology. 1986;43:24-31.

32. Naum OG, Fernanda Rubio M, Golombek DA. Rhythmic variation in gamma-aminobutyric acid(A)-receptor subunit composition in the circadian system and median eminence of Syrian hamsters. Neurosci Lett. 2001;310:178-82.

33. Lang N, Rothkegel $H$, Reiber $H$, Hasan A, Sueske E, Tergau F, et al. Circadian modulation of GABA-mediated cortical inhibition. Cereb Cortex. 2011;21:2299-306.

34. Sánchez S, Sánchez C, Paredes SD, Cubero J, Rodríguez AB, Barriga C. Circadian variations of serotonin in plasma and different brain regions of rats. Mol Cell Biochem. 2008;317:105-11.

35. Wesemann W, Rotsch M, Schulz E, Sturm G, Zöfel P. Circadian rhythm of serotonin binding in rat brain--I. Effect of the light-dark cycle. Chronobiol Int. 1986;3:135-9.

36. Hofman MA. Evolution of the human brain: when bigger is better. Front Neuroanat. 2014;8:15.

37. Sun Y, Sun X, Qu H, Zhao S, Xiao T, Zhao C. Neuroplasticity and behavioral effects of fluoxetine after experimental stroke. Restor Neurol Neurosci. 2017;35:457-68.

38. Werner JK, Stevens RD. Traumatic brain injury: recent advances in plasticity and regeneration. Curr Opin Neurol. 2015;28:565-73.

39. Hut RA, Van der Zee EA. The cholinergic system, circadian rhythmicity, and time memory. Behav Brain Res. 2011;221:466-80.

40. González Burgos GR, Rosenstein RE, Cardinali DP. Daily changes in presynaptic cholinergic activity of rat sympathetic superior cervical ganglion. Brain Res. 1994;636:181-6.

41. Mash DC, Flynn DD, Kalinoski L, Potter LT. Circadian variations in radioligand binding to muscarine receptors in rat brain dependent upon endogenous agonist occupation. Brain Res. 1985;331:35-8.

42. Pike BR, Hamm RJ. Activating the posttraumatic cholinergic system for the treatment of cognitive impairment following traumatic brain injury. Pharmacol Biochem Behav. 1997;57:785-91.

43. DeAngelis MM, Hayes RL, Lyeth BG. Traumatic brain injury causes a decrease in M2 muscarinic cholinergic receptor binding in the rat brain. Brain Res. 1994;653:39-44.

44. Corthell JT, Stathopoulos AM, Watson CC, Bertram R, Trombley PQ. Olfactory bulb monoamine concentrations vary with time of day. Neuroscience. 2013;247:234-41. 
Rev Mex Neuroci. 2020;21(1)

45. Ikeda E, Matsunaga N, Kakimoto K, Hamamura K, Hayashi A, Koyanagi S, et al. Molecular mechanism regulating 24-hour rhythm of dopamine D3 receptor expression in mouse ventral striatum. Mol Pharmacol. 2013;83:959-67.

46. Fifel K, Cooper HM. Loss of dopamine disrupts circadian rhythms in a mouse model of Parkinson's disease. Neurobiol Dis. 2014;71:359-69.

47. Orient-López F, Terre- Boliart R, Bernabeu-Guitart M, Ramón-Rona S, Pérez-Miras $A$. The usefulness of dopaminergic drugs in traumatic brain injury. Rev Neurol. 2002;35:362-6.
48. He X, Sandhu HK, Yang Y, Hua F, Belser N, Kim DH, et al. Neuroprotection against hypoxia/ischemia: $\delta$-opioid receptor-mediated cellular/ molecular events. Cell Mol Life Sci. 2013;70:2291-303.

49. Gomes CV, Kaster MP, Tomé AR, Agostinho PM, Cunha RA. Adenosine receptors and brain diseases: neuroprotection and neurodegeneration. Biochim Biophys Acta. 2011;1808:1380-99.

50. Shohami E, Cohen-Yeshurun A, Magid L, Algali M, Mechoulam R. Endocannabinoids and traumatic brain injury. $\mathrm{Br} J$ Pharmacol. 2011; 163:1402-10. 